\title{
The geography of new business formation in the Czech Republic: a cross-section analysis (2003-2014)
}

\author{
Jiří Novosák* ${ }^{\mathrm{a}}$, Jana Novosáková ${ }^{\mathrm{b}}$, Oldřich Hájek ${ }^{\mathrm{a}}$, \\ Joanna Górska-Szymczak ${ }^{c}$ \\ a Newton College, Czech Republic \\ $b$ University of St. Cyril and Methodius in Trnava, Slovakia \\ c Jagiellonian College Toruń, Poland
}

The intent of this paper is to provide empirical evidence of determinants on new business formation in the Czech Republic's regions in the period 2003 to 2014. The results suggest that the regions with strong entrepreneurial culture, measured by a high proportion of entrepreneurs in the population, and with a strong presence of foreigners, had higher rates of new business formation. A positive influence of agglomeration economies was observed, and the impact of unemployment was negative. However, the results were not consistent when more advanced legal business forms (especially limited liability and joint-stock companies) had been used in the dependent variable. In this case, human capital was the overriding factor determining regional differences in new business formation rates, while entrepreneurial culture and the presence of foreigners were not significant. Finally, the importance of the industrial structure of regions was confirmed regardless of the dependent variable form.

Key Words: new business formation, regional determinants, regional disparities.

Article Info: Received: May 15, 2017; Revised: October 15, 2017; Accepted: November 13, 2017; Online: November 25, 2017.

\section{Introduction}

The end of communism in the late 1980s and early 1990s meant that central planning was gradually replaced by market mechanisms. The associated pro-

\section{* Corresponding author}

Address: Newton College, Politických vězňů 912/10, 11000 Prague, Czech Republic.

Phone: +420222 200325 | Email: Jiri.Novosak@newtoncollege.cz

(C)2017 Human Geographies; The authors

(c) (i) This work is licensed under a

Creative Commons Attribution 4.0 International License. DOI:10.5719/hgeo.2017.112.3 
cesses were accompanied by the core task of adapting economies to those changes, and a key changing role was ascribed to entrepreneurship (Winiecki, 2003; Earle \& Sakova, 2000; Milichovský \& Koleňák, 2014; Wyrwich, 2012; Smallbone \& Welter, 2006; Janíček, 2017). Consequently, the number of enterprises skyrocketed in the first years of post-communist transformation. Moreover, new enterprises have become apparent as the source of structural change, economic growth and employment (Danis \& Shipilov, 2012; Wyrwich, 2012; Dolinská \& Ambrozová, 2015), motivating research on entrepreneurship and new business formation in post-communist countries.

Increasing regional disparities have been another feature of post-communist transformation since its onset in the early 1990s (Ezcurra, Pascual \& Rapún, 2007; Czyz \& Hauke, 2011; Smetkowski, 2013). Several authors mention the link between entrepreneurship on the one hand and the nature of regional disparities on the other (Novák \& Netrdová, 2011; Barjak, 2001), thereby stimulating the interest in researching regional determinants of new business formation. However, most of these studies concerned 'old' capitalist countries (Bishop, 2012; Fotopoulos, 2014; Delfmann et al., 2014; Armington \& Acs, 2002) while only a few studies dealt with determinants of new business formation in the post-communist context (Wyrwich, 2012; Lafuente \& Vaillant, 2010; Fritsch et al., 2014; Hájek, Nekolová \& Novosák, 2015 as notable exceptions). Therefore, this paper, aiming to identify regional determinants of new business formation in the Czech Republic (2003-2014), adds some new evidence to the research debate.

The remainder of this paper proceeds as follows. The next section reviews the theoretical background for determinants of new business formation. The methods used in this paper are introduced in the section following this review. Then the empirical results are presented and discussed. In the last section, the authors draw conclusions.

\section{Theoretical framework}

The regional determinants of new business formation have been researched using a number of theoretical bases. Delfmann et al. (2014) describe a general theoretical framework that integrates demand-side and supply-side factors, and also the institutional environment, for explaining regional differences in new business formation. The demand-side factors relate to entrepreneurial opportunities, whereas the supply-side factors relate to people's resources, traits and attitudes to entrepreneurship, and the institutional environment relates to sociocultural aspects of entrepreneurship. Moreover, new business formation rates differ regarding industries because entrepreneurial opportunities and barriers are not the same for all industries (Fotopoulos, 2014; Wyrwich, 2012). Altogether, this general theoretical framework may be used for defining the determinants of new business formation.

Agglomeration economies have frequently been examined as a predictive demand-side factor for new business formation. Three types of agglomeration economies are generally considered: (a) the availability of the pooled labour force; (b) non-pecuniary externalities; and (c) knowledge and information 
spillovers (Lafuente \& Vaillant, 2010; Armington \& Acs, 2002). New businesses locate themselves in order to take advantage of agglomeration economies (Audretsch \& Fritsch, 1994) that have been measured in a number of different ways, including population density (Bishop, 2012; Audretsch \& Fritsch, 1994; Lafuente \& Vaillant, 2010) and the quality of human capital (Wyrwich, 2012; Lee, Florida \& Acs, 2004; Armington \& Acs, 2002). Human capital is also regarded to be a supply-side factor of new business formation because it is claimed that better-educated people are more equipped to identify and exploit entrepreneurial opportunities (Fotopoulos, 2014; Lee, Florida \& Acs, 2004).

The theory of knowledge spillovers closely relates to demand-side factors of new business formation. The essence of this theory is that new knowledge is not fully exploited by the creators (Bishop, 2012). Subsequently, 'unused' knowledge is the source of entrepreneurial opportunities. It is claimed that the greater the stock of local knowledge, the more entrepreneurial opportunities may arise and be exploited, resulting in high new business formation rates (Bishop, 2012; Lee, Florida \& Acs, 2004). In this regard, spatial proximity and the quality of human capital that enhance knowledge spillovers are essential elements of the theory (Fotopoulos, 2014; Bishop, 2012). The stock of local knowledge has been empirically measured in different ways, including patent activities (Lee, Florida \& Acs, 2004).

Unemployment has been another frequently examined determinant of new business formation. Two contradictory views are commonly held in existing literature regarding the influence of unemployment on new business formation. On the one hand, unemployment means less entrepreneurial opportunities because it constrains demand, negatively influencing new business formation rates (Delfmann et al., 2014; Lafuente \& Vaillant, 2010). On the other hand, unemployment increases the supply of potential entrepreneurs, positively influencing new business formation rates (Bishop, 2012; Armington \& Acs, 2002; Audretsch \& Fritsch, 1994). Therefore, the nature of unemployment's influence on new business formation is not apriori clear (Fotopoulos, 2014; Bishop, 2012; Wyrwich, 2012).

The higher propensity of foreigners establishing their businesses is another supply-side factor of new business formation. Lee, Florida \& Acs (2004), Delfmann et al. (2014) explain this by noting that: (a) foreigners are disadvantaged in the labour market, owing to low education and language barriers; (b) foreigners are more willing to be risk-takers; and (c) foreigners bring with them their own culture, skills and lifestyle. Consequently, higher proportions of foreigners in the population are expected to positively influence new business formation rates.

A number of recent studies have shown the persistence of new business formation (Fotopoulos, 2014; Anderson \& Koster, 2011; Fritsch \& Mueller, 2007). Several mechanisms have been proposed in the research literature for explaining this effect, including agglomeration economies and externalities, selfreinforcing processes, and entrepreneurial culture. Therefore, high rates of new business formation in the past tend to positively influence high rates of new business formation in the future (Anderson \& Koster, 2011; Fotopoulos, 2014).

The regional determinants of new business formation have been mostly examined in 'old' capitalist countries. Research in post-communist contexts has 
been less frequent due to, among others reasons, the lack of data (Lafuente \& Vaillant, 2010). However, the existing studies point out some specific features of the early phase of post-communist transformation. These features include the little effect by agglomeration economies (Wyrwich, 2012; Lafuente \& Vaillant, 2010), the strong influence of the need to 'push' entrepreneurship through unemployment (Fritsch et al., 2014; Earle \& Sakova, 2000) and the strong influence of the quality of human capital (Fritsch et al., 2014; Smallbone \& Welter, 2006) on new business formation rates.

This paper adds to the limited literature on the regional determinants of new business formation in post-communist countries by examining their influence on new business formation rates in the Czech Republic (2003-2014). The period is, apart from partially altered regional determinants, the main continuation of the research carried out by Hájek, Nekolová and Novosák (2015) in which they only dealt with the period 2011-2012. Additionally, new business is defined by considering two forms of businesses - natural persons and business corporations as legally more advanced business entities.

\section{Methodology}

The methodology of this paper is based on regression analysis in which the dependent variable is new business formation rates, and the explanatory variables relate to theoretically meaningful regional variables. All the variables refer to the administrative districts of municipalities with extended power (205 units in total), and to the territory of the capital city of Prague (hereafter referred to as regions). The regions are administrative-territorial units, corresponding to the areas between level LAU1 and LAU2.

In this research, a new business is identified from each new identification number registered in the Business Register of the Czech Republic (hereafter referred to as BR CR) in the period 2003-2014, and the end of year state is considered of each year between 2003 and 2014. Generally, the two main legal forms of new businesses in the Czech Republic are natural persons (or 'entrepreneurs'), and also legally more advanced business entities (hereafter referred to as 'business corporations'). The latter especially includes limited liability companies and joint-stock companies. Two forms of the dependent variable are employed to reveal the specifics of business corporations: (1) all new businesses; and (2) business corporations only. Moreover, the labour market approach is used to standardise the number of new businesses to be independent of regional size (Armington \& Acs, 2002; Audretsch \& Fritsch, 1994). Hence, the number of new businesses in a region, in either of the forms, is divided by the number of people in the productive age groups. Finally, the dependent variable is logtransformed to approximate the normality assumption of the residuals more closely.

The explanatory variables are derived from the theoretical framework outlined in the preceding section, and dated from 2005 or earlier, minimising endogeneity issues (Bishop, 2012). Three explanatory variables relate to agglomeration economies and the theory of knowledge spillovers: (1) population density, measured as inhabitants per square kilometre in 2003 (DENSITY); (2) 
the quality of human capital measured as the mean of the years of schooling of the region's population aged 15 and over in 2001 (HUMAN CAPITAL); and (3) the stock of local knowledge measured as the number of patents and utility models per population aged 15-64, and calculated as the mean of the 2002-2005 rates (KNOWLEDGE). The Czech Statistical Office (hereafter referred to as CSO) is the source of data for the DENSITY and HUMAN CAPITAL variables, while data about patents is taken from the Industrial Property Office (hereafter referred to as IPO).

Two explanatory variables relate to the supply-side factors of new business formation. Firstly, unemployment is the number of registered unemployed people in the region's population aged 15-64, calculated as the mean of the 2003-2005 rates (UNEMPLOYMENT). CSO is the source of data. Secondly, the ratio of foreigners to the number of people in the productive age groups is also calculated as the mean of the 2003-2005 rates (FOREIGNERS). Data on foreigners and the number of people in the productive age groups are taken from the Ministry of Interior (hereafter referred to as MoI) and CSO respectively.

The institutional factors of entrepreneurial culture are proxied by entrepreneurial activity in a particular region at the beginning of the 2003-2014 period. It is measured as the share of employers and self-employed people in the economically active population in 2001 (ENTREPRENEURIAL CULTURE), assuming that high entrepreneurial activity is associated with favourable entrepreneurial culture. CSO is the source of data.

Finally, four explanatory variables are added to check differences in the industrial structure of various regions. These variables are derived by using factor analysis on the CSO data for the proportion of people employed in 9 industries and 206 regions, in 2001. In this regard, three variables are directly the share of employment in the economically active population, in 2001, in the sectors (1) agriculture, forestry and fisheries (PRIMARY SECTOR); (2) construction (CONSTRUCTION); and (3) accommodation and food service activities (TOURISM). These variables were excluded from the factor analysis because they had a low value of the measure of sampling adequacy. The remaining six industries were entered into the principal component analysis, extracting an only factor, with positive loadings on financial services, business services, wholesale and retail trade, public services, transportation, and with negative loadings on manufacturing. Therefore, the factor considers the importance of manufacturing and services in a regional economy. Note that the resulting factor scores (MANUFACTURING-SERVICE) are used in subsequent analyses, and the reliability of the factor is adequate as shown by the coefficient 'alpha'.

Correlation and regression analyses are used to identify regional determinants associated with the rates for new business formation. Firstly, the regression models are estimated by applying linear least squares (OLS) with White's correction for heteroscedasticity. However, the presence of spatial autocorrelation makes the OLS estimates inconsistent and biased. The generalised method of moments (GMM) spatial error models with heteroscedasticity robust standard errors are, therefore, estimated based on the results of the Lagrange Multiplier (LM) tests as suggested by Anselin et al. (1996) and others. Note that the other usual regression assumptions were checked by performing residual diagnostics on the models, and a violation was not detected. 


\section{Empirical results}

Figures 1 and 2 provide the first insights into the spatial distribution of new business formation rates. Three findings are noteworthy here. Firstly, the spatial distribution of new business formation rates is not accidental since both - spatial clusters of high values of new business formation rates and also spatial clusters of low values of new business formation rates - are present. The presence of significant spatial autocorrelation is also confirmed by Moran's I statistic. This is 0.380 for all businesses and 0.224 specifically for business corporations only. Hence, spatial clustering of the regions sharing similar new business formation rates is suggested.

Secondly, the level of new business formation is rather high in major urban areas and their surroundings, which indicates the importance of agglomeration economies for new business formation rates. Thirdly, the differences between the two forms of new business formation rates are illustrated in both figures, also suggesting that regional determinants may differ between them. Overall, the findings substantiate the empirical strategy used in this paper.

Table 1 adds to our knowledge base by exploring bivariate correlations between the explanatory variables and the new business formation rates. The three explanatory variables related to agglomeration economies and the theory of knowledge spillovers (DENSITY, HUMAN CAPITAL and KNOWLEDGE) are positively and significantly correlated with new business formation rates. The positive and significant correlation is also found between the FOREIGNERS and ENTREPRENEURIAL CULTURE variables, while it is negative for the UNEMPLOYMENT variable. Finally, high shares of employment in (1) construction (CONSTRUCTION); (2) accommodation and food service activities (TOURISM); and (3) service industries (MANUFACTURING-SERVICE) are positively associated with new business formation rates, while high shares of

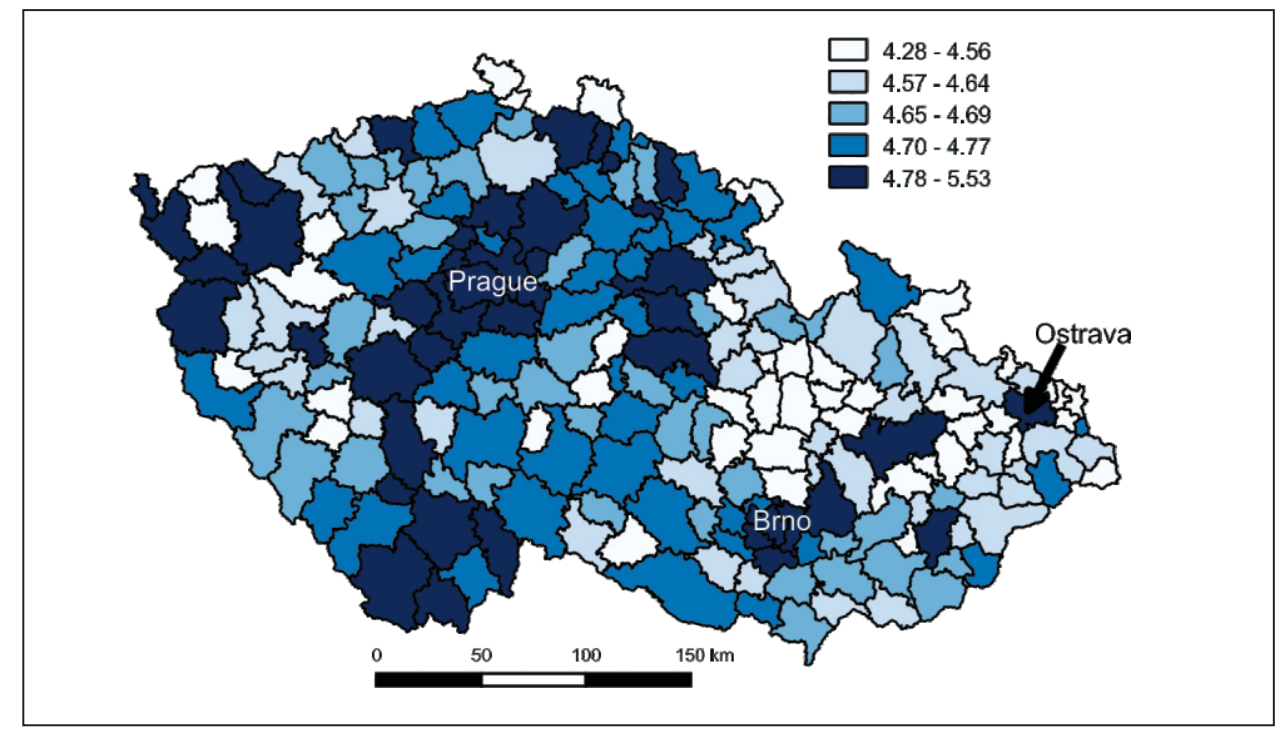

Figure 1. New business formation rate - all businesses (2003-2014), Czech regions Source: own elaboration based on BR CR, and CSO 


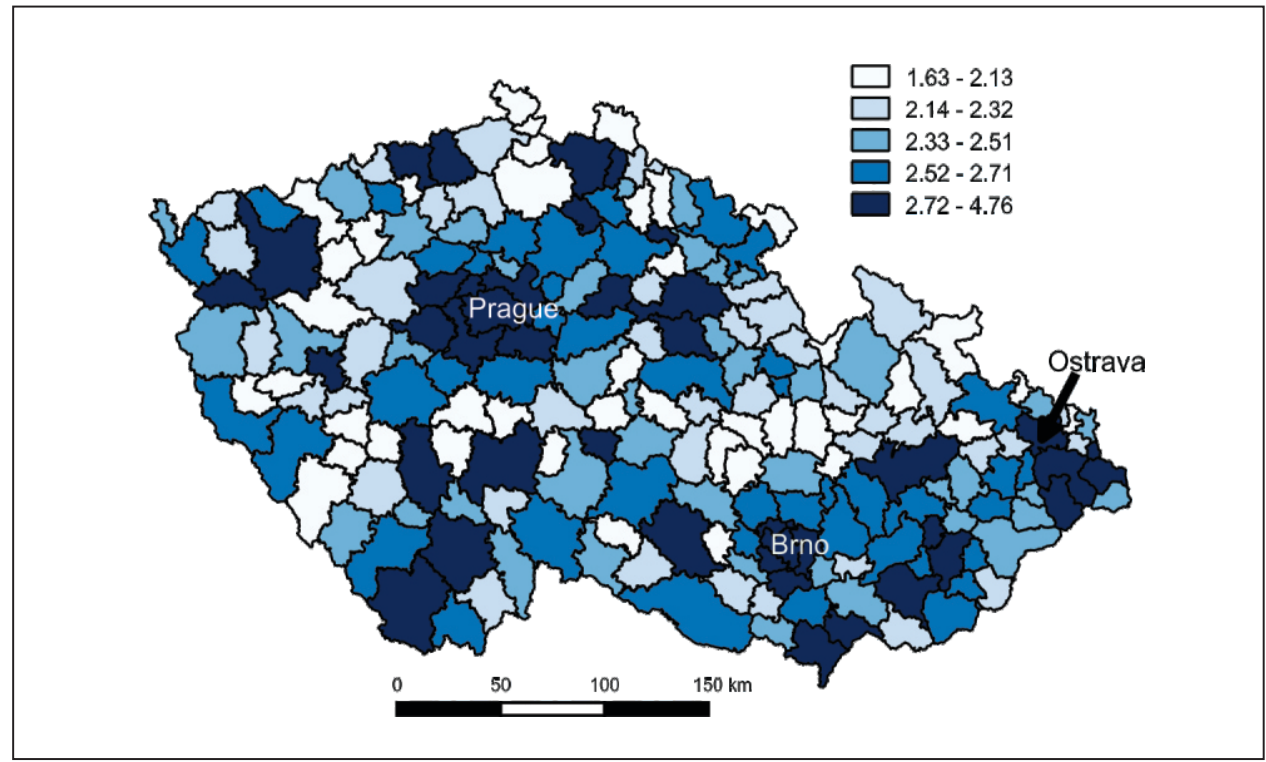

Figure 2. New business formation rate - business corporations (2003-2014), Czech regions Source: own elaboration based on BR CR, and CSO

Table 1. Pearson correlation coefficients

\begin{tabular}{lcr}
\hline \multicolumn{1}{c}{ Variable } & All businesses & Business corporations \\
\hline Density & $0.348^{* *}$ & $0.536^{* *}$ \\
\hline Human capital & $0.545^{* *}$ & $0.721^{* *}$ \\
\hline Knowledge & $0.169^{*}$ & $0.280^{* *}$ \\
\hline Unemployment & $-0.420^{* *}$ & $-0.257^{* *}$ \\
\hline Foreigners & $0.595^{* *}$ & $0.387^{* *}$ \\
\hline Entrepreneurial culture & $0.660^{* *}$ & $0.433^{* *}$ \\
\hline Primary sector & $-0.247^{* *}$ & $-0.470^{* *}$ \\
\hline Construction & $0.157^{*}$ & 0.029 \\
\hline Tourism & $0.335^{* *}$ & $0.287^{* *}$ \\
\hline Manufacturing-service & $0.634^{* *}$ & $0.728^{* *}$ \\
\hline ** significant at the 0.01 significance level; ${ }^{*}$ significant at the 0.05 significance level \\
Source: own elaboration based on BR CR, CSO, IPO, and Mol
\end{tabular}

employment in agriculture, forestry and fisheries (PRIMARY SECTOR) are negatively associated with new business formation rates.

The correlations are as expected according to the theory and the correlations are stable for the two forms of new business formation rates. However, some differences between these two forms may be observed regarding the strength of correlations. The three explanatory variables related to agglomeration economies and also related to the theory of knowledge spillovers (DENSITY, HUMAN CAPITAL and KNOWLEDGE), and the variables related to a more serviceoriented economy (MANUFACTURING-SERVICE, PRIMARY SECTOR) are more strongly associated with business corporations, but the remaining five variables relate to all businesses. Hence, it seems that new business corporations are more likely to be established in major urban areas. 
Table 2. Regression model estimates (standardized coefficients reported)

\begin{tabular}{|c|c|c|c|c|}
\hline \multirow[t]{2}{*}{ Variable } & \multicolumn{2}{|c|}{ All businesses } & \multicolumn{2}{|c|}{ Business corporations } \\
\hline & OLS model & SE model & OLS model & SE model \\
\hline Density & $\begin{array}{r}0.107 \\
(0.062) \\
\end{array}$ & $\begin{array}{c}0.131^{*} \\
(0.051)\end{array}$ & $\begin{array}{r}0.106 \\
(0.057) \\
\end{array}$ & $\begin{array}{r}0.107^{*} \\
(0.054)\end{array}$ \\
\hline Human capital & $\begin{array}{c}0.157^{*} \\
(0.068)\end{array}$ & $\begin{array}{r}0.138 \\
(0.071)\end{array}$ & $\begin{array}{l}0.385^{* *} \\
(0.064)\end{array}$ & $\begin{array}{l}0.335^{* *} \\
(0.064)\end{array}$ \\
\hline Knowledge & $\begin{array}{c}-0.029 \\
(0.035) \\
\end{array}$ & $\begin{array}{c}-0.001 \\
(0.033) \\
\end{array}$ & $\begin{array}{r}0.006 \\
(0.038) \\
\end{array}$ & $\begin{array}{r}0.018 \\
(0.036) \\
\end{array}$ \\
\hline Unemployment & $\begin{array}{c}-0.137^{* *} \\
(0.050) \\
\end{array}$ & $\begin{array}{c}-0.130^{* *} \\
(0.050) \\
\end{array}$ & $\begin{array}{c}-0.084 \\
(0.054) \\
\end{array}$ & $\begin{array}{r}-0.108 \\
(0.058) \\
\end{array}$ \\
\hline Foreigners & $\begin{array}{l}0.392^{* *} \\
(0.064)\end{array}$ & $\begin{array}{l}0.346^{* *} \\
(0.069)\end{array}$ & $\begin{array}{r}0.097 \\
(0.053) \\
\end{array}$ & $\begin{array}{r}0.058 \\
(0.060) \\
\end{array}$ \\
\hline Entrepreneurial culture & $\begin{array}{l}0.259^{* *} \\
(0.060)\end{array}$ & $\begin{array}{l}0.269^{* *} \\
(0.063)\end{array}$ & $\begin{array}{c}-0.014 \\
(0.056) \\
\end{array}$ & $\begin{array}{r}0.053 \\
(0.059) \\
\end{array}$ \\
\hline Primary sector & $\begin{array}{r}0.019 \\
(0.041)\end{array}$ & $\begin{array}{c}-0.022 \\
(0.042)\end{array}$ & $\begin{array}{c}-0.195^{* *} \\
(0.043)\end{array}$ & $\begin{array}{r}-0.226^{* *} \\
(0.045)\end{array}$ \\
\hline Construction & $\begin{array}{l}0.137^{* *} \\
(0.043)\end{array}$ & $\begin{array}{c}0.116^{*} \\
(0.050)\end{array}$ & $\begin{array}{r}0.092^{*} \\
(0.042)\end{array}$ & $\begin{array}{r}0.039 \\
(0.039)\end{array}$ \\
\hline Tourism & $\begin{array}{l}0.103^{* *} \\
(0.036)\end{array}$ & $\begin{array}{l}0.109^{* *} \\
(0.038)\end{array}$ & $\begin{array}{l}0.162^{* *} \\
(0.052)\end{array}$ & $\begin{array}{l}0.145^{* *} \\
(0.049)\end{array}$ \\
\hline Manufacturing-service & $\begin{array}{l}0.200^{* *} \\
(0.049)\end{array}$ & $\begin{array}{l}0.190^{* *} \\
(0.053)\end{array}$ & $\begin{array}{l}0.290^{* *} \\
(0.048)\end{array}$ & $\begin{array}{l}0.302^{* *} \\
(0.048)\end{array}$ \\
\hline Coefficient $\lambda$ & - & $\begin{array}{l}0.422^{* *} \\
(0.093)\end{array}$ & - & $\begin{array}{l}0.393^{* *} \\
(0.081) \\
\end{array}$ \\
\hline Observations & 206 & 206 & 206 & 206 \\
\hline Adjusted $R^{2} /$ Pseudo $R^{2}$ & 0.75 & 0.75 & 0.73 & 0.74 \\
\hline
\end{tabular}

\section{Discussion}

The empirical results presented in the preceding section are further analysed by using regression analysis in this section. Besides the usual OLS cross-section estimation, spatial error models were performed to check for spatial dependence and also to make statistical estimates more robust. Table 2 provides the regression results, which reports standardised coefficients. These were chosen to compare the influence of the explanatory variables on new business formation rates. The first two models concern all businesses, while the latter two models concern only business corporations.

The presence of foreigners in a region (FOREIGNERS) and their entrepreneurial culture (ENTREPRENEURIAL CULTURE) are the most influential predictors of new business formation rates in the first two models. However, the influence of these two variables is not significant in the latter two models. This means that the proportion of foreigners to the number of people in the productive age groups, and also the share of employers and self-employed people in the economically active population at the beginning of the 2003-2014 period, both have the strongest impacts on new business formation of all legal forms, but they do not have this strong impact on business corporations. Thus, the results support the theoretical assumptions that: (1) foreigners are more likely to 
establish their own businesses; and (2) new businesses are more likely to be founded in an entrepreneurially rich environment; nevertheless entrepreneurs are engaged in their business only as natural persons, and they do not establish legally more complicated business forms. Thus, other variables are significant for explaining spatial variation in new business corporation formation rates.

The quality of human capital in a region (HUMAN CAPITAL) is the most influential predictor of new business corporation formation rates. Better educated people are more equipped to deal with the processes required for establishing a new business corporation. However, this relationship is weakened and even insignificant in the spatial error model when considering the two models calculated with all new businesses in the dependent variable. It means that education is not significant in determining whether or not a person will conduct business as a natural person (compare this stance with the hypothesis of the importance of human capital in Fritsch et al., 2014; Smallbone \& Welter, 2006).

Agglomeration economies, proxied by population density (DENSITY), have positive influences on new business formation rates, regardless of the dependent variable form. It is noteworthy that the variable is only significant in the spatial error models at the 0.05 significance level (compare this with a similar hypothesis of the low effects of agglomeration economies in Wyrwich, 2012; Lafuente \& Vaillant, 2010). The store of local knowledge, measured as the number of patents and utility models per population aged 15-64 (KNOWLEDGE), is not significant in either of the models. Local knowledge may be more important for certain industries than for overall evaluation. The unemployment rate (UNEMPLOYMENT) has negative impact on new business formation rates, indicating that the demand-side influence of unemployment is more important than the supply-side influence (compare this with the hypothesis of the importance of necessity entrepreneurship 'pushed' by unemployment in Fritsch et al., 2014; Earle \& Sakova, 2000). Nevertheless, the impact is significant in the dependent variable only, in the two models for all new businesses.

Finally, table 2 confirms the importance of the industrial structure of regions for explaining the differences in new business formation rates. In this regard, a high share of employment in services (MANUFACTURING-SERVICE) is the strongest positive predictor of new business formation rates in all the models. Similarly, employment in accommodation and food service activities (TOURISM) has a positive and significant influence on new business formation rates, regardless of the form of the dependent variable. On the contrary, a relatively large employment in the primary sector (PRIMARY SECTOR) is associated with a lower new business formation rate, but only for new business corporations. The opposite is true for employment in construction (CONSTRUCTION). Hence, a higher tendency is indicated to conduct business as a natural person in these two industries.

\section{Conclusions}

The goal of this paper was to identify regional determinants of new business formation in the Czech Republic in the period 2003-2014, contributing to 
knowledge in this field in often neglected post-communist country situations. The results brought the following findings to light.

New business formation varied considerably among the Czech Republic's regions during 2003 to 2014. Both, 'hot spots' and 'cold spots' were identified in this regard. There was a clear tendency for spatial clustering, evoking the question of which regional factors best explain the differences in new business formation rates.

Concerning all new businesses, the strongest predictors of new business formation rates were the proportion of foreigners in the productive age population, and also the proportion of employers and self-employed people in the economically active population at the beginning of the period 2003-2014. Hence, the regions with strong entrepreneurial culture and with a strong presence of foreigners had higher new business formation rates. These rates were further increased in the presence of agglomeration economies and when unemployment was low. Hence, the demand constraints stemming from unemployment were of higher importance than the increasing supply of potential entrepreneurs. Human capital, measured as the years of schooling, was not significant for explaining regional differences in new business formation rates.

However, this scenario was not repeated when new business corporation formation rates were used as the dependent variable. It was shown that human capital, and not the presence of foreigners and strong entrepreneurial culture, was the decisive factor determining regional differences in new business corporation formation rates. Hence, the presence of foreigners and the number of entrepreneurs in a region led to legally less complicated business forms, whereas human capital was a significant determinant for conducting business in the form of a limited liability or joint-stock company. The positive influence of agglomeration economies was also noticed for business corporations.

The importance of regional industrial structure was confirmed, regardless of the dependent variable form. Hence, service-oriented regional economies had higher new business formation rates than manufacturing-oriented regional economies. Moreover, there was clear detection that a strong tourism sector had a positive impact, as also a strong construction sector had a positive impact, and a strong primary sector had a negative impact on new business formation.

Overall, the results support the theoretical principles about the determinants of new business formation, and the results provide the sign of the regression coefficients, as expected. Some specific characteristics of post-communist countries suggested in the literature were also observed. These characteristics particularly concern the effects of agglomeration economies, whose importance was reduced under communist governments. It is anticipated that the influence of agglomeration economies will increase in future (Ezcurra, Pascual \& Rapún, 2007; Nekolová, Novosák \& Hájek, 2016), as suggested also by the work of Hájek, Nekolová \& Novosák (2015) who found statistically significant influence of agglomeration economies on new business formation rates in the time period 2011-2012. On the contrary, the effects of entrepreneurial culture and the presence of foreigners on new business formation rates remain the same as in the work of Hájek, Nekolová \& Novosák (2015); however, not for business corporations. Methodologically, these findings clearly illustrate the importance of different legal business forms for determining the influence of regional 
determinants on new business formation rates and this is the main contribution of this paper to the previous work of Hájek, Nekolová \& Novosák (2015).

\section{References}

Anderson, M. and Koster, S. (2011), 'Sources of persistence in regional start-up rates - evidence from Sweden', Journal of Economic Geography, vol. 11, no. 1, pp. 179-201.

Anselin, L., Bera, A.K., Florax, R. and Yoon, M.J. (1996), 'Simple diagnostic tests for spatial dependence', Regional Science and Urban Economics, vol. 26, no. 1 , pp. 77-104.

Armington, C. and Acs, Z.J. (2002), 'The determinants of regional variation in new firm formation', Regional Studies, vol. 36, no. 1, pp. 33-45.

Audretsch, D.B. and Fritsch, M. (1994), 'The geography of firm births in Germany', Regional Studies, vol. 28, no. 4, pp. 359-365.

Barjak, F. (2001), 'Regional disparities in transition economies: a typology for East Germany and Poland', Post-Communist Economies, vol. 13, no. 3, pp. 289311.

Bishop, P. (2012(, 'Knowledge, diversity and entrepreneurship: a spatial analysis of new firm formation in Great Britain', Entrepreneurship and Regional Development, vol. 24, no. 7-8, pp. 641-660.

Czyz, T. and Hauke, J. (2011), 'Evolution of regional disparities in Poland', Quaestiones Geographicae, vol. 30, no. 2, pp. 35-48.

Danis, W.D. and Shipilov, A.V. (2002), 'A comparison of entrepreneurship development in two post-communist countries: the cases of Hungary and Ukraine', Journal of Developmental Entrepreneurship, vol. 7, no. 1, pp. 67-94.

Delfmann, H., Koster, S., McCann, P. and van Dijk, J. (2014), 'Population change and new firm formation in urban and rural regions', Regional Studies, vol. 48, no. 6, pp. 1034-1050.

Dolinská, V. and Ambrozová, E. (2015), 'Problems of organizational culture in economic and educational environment', Scientia Ė Societas, vol. 11, no. 1, pp. 88-98.

Earle, J.S. and Sakova, Z. (2000), 'Business start-ups or disguised unemployment? Evidence on the character of self-employed from transition economies', Labour Economics, vol. 7, no. 5, pp. 575-601.

Ezcurra, R., Pascual, P. and Rapún, M. (2007), 'The dynamics of regional disparities in Central and Eastern Europe during transition', European Planning Studies, vol. 15, no. 10, pp. 1397-1421.

Fotopoulos, G. (2014), 'On the spatial stickiness of UK new firm formation rates', Journal of Economic Geography, vol. 14, no. 3, pp. 651-679.

Fritsch, M., Bublitz, E., Sorgner, A. and Wyrwich, M. (2014), 'How much of a socialist legacy? The re-emergence of entrepreneurship in the East German transformation to a market economy', Small Business Economics, vol. 43, no. 2, pp. 427-446.

Fritsch, M. and Mueller, P. (2007), 'The persistence of regional new business formation-activity over time - assessing the potential of policy promotion programs', Journal of Evolutionary Economics, vol. 17, no. 3, pp. 299-315. 
Hájek, O., Nekolová, J. and Novosák, J. (2015), 'Determinants of new business formation - some lessons from the Czech Republic', Economics E Sociology, vol. 8, no. 1, pp. 147-156.

Janíček, P. (2017), 'European support for private profit-oriented entities in Slovak regions', International Journal of Public Administration, Management and Economic Development, vol. 2, no. 1, pp. 49-55.

Lafuente, E. and Vaillant, Y. (2010), 'Regional differences in new firm formation: evidence from Romania', Centre for Entrepreneurship \& Business Research Working Paper Series, vol. 1, no. 1, pp. 1-36.

Lee, S.Y., Florida, R. and Acs, Z.J. (2004), 'Creativity and entrepreneurship: a regional analysis of new firm formation', Regional Studies, vol. 38, no. 8, pp. 879-891.

Milichovský, F. and Koleňák, J. (2014), 'Methodology for the selection of compensation trade tools in SMEs', Danube, vol. 5, no. 3, pp. 213-224.

Nekolová, J., Novosák, J. and Hájek, O. (2016), 'The changing determinants of new business formation in the Czech Republic', Montenegrin Journal of Economics, vol. 12, no. 1, pp. 7-20.

Novák, J. and Netrdová, P. (2011), 'Spatial patterns of socioeconomic differentiation in the Czech Republic at the level of municipalities', Czech Sociological Review, vol. 47, no. 4, pp. 717-744.

Smallbone, D. and Welter, F. (2006), 'Conceptualising entrepreneurship in a transition context', International Journal of Entrepreneurship and Small Business, vol. 3, no. 2, pp. 190-206.

Smetkowski, M. (2013), 'Regional disparities in Central and Eastern European countries: trends, drivers and prospects', Europe-Asia Studies, vol. 65, no. 8, pp. 1529-1554.

Winiecki, J. (2003), 'The role of the new, entrepreneurial private sector in transition to economic performance in light of the successes in Poland, the Czech Republic, and Hungary', Problems of Economic Transition, vol. 45, no. 11, pp. 6-38.

Wyrwich, M. (2012), 'Regional entrepreneurial heritage in a socialist and a postsocialist economy', Economic Geography, vol. 88, no. 4, pp. 423-445. 